\title{
Design of Fault-Tolerant Dual Three-Phase Winding PMSM for Helicopter Landing Gear EMA
}

\author{
Paolo Giangrande ${ }^{1}$, Vincenzo Madonna ${ }^{1}$, Stefano Nuzzo $^{1}$, Michael Galea ${ }^{1,2}$ \\ ${ }^{1}$ Power Electronics, Machines and Control Group, University of Nottingham, Nottingham, UK, p.giangrande@,nottingham.ac.uk \\ ${ }^{2}$ School of Aerospace, University of Nottingham Ningbo, Ningbo, China
}

\begin{abstract}
On modern rotorcraft, electro-mechanical actuators (EMAs) are progressively replacing the bulky and more expensive hydraulic and/or pneumatic systems. Although the migration towards alternative actuation solutions, reliability remains a key requirement for aerospace applications. Fault-tolerant electrical machines are often employed for ensuring the demanded reliability level. In this paper, the design of a dual three-phase winding permanent magnet synchronous machine (PMSM) for helicopter nose landing gear extension/retraction EMA is addressed. Finite element (FE) simulations are used for evaluating the PMSM performance in both healthy and faulty conditions. The compensation strategy implemented on the healthy three-phase winding, while the second one is completely shorted, is also discussed. Finally, a purposely built dual three-phase winding PMSM model is implemented in Dymola environment, where the extension/retraction EMA is simulated. Hence, EMA behaviour under both healthy and faulty conditions is analysed.
\end{abstract}

Keywords-Dual Three-Phase Winding, PMSM, Fault-Tolerant Capability, EMA, Landing Gear, Dymola.

\section{INTRODUCTION}

The landing gear (LG) represents an essential component for helicopter functionality, as it supports the rotorcraft weight during landing and take-off. For helicopters employed in air transport, retractable LGs are often preferred to fix LGs, since they allow higher speeds and improve the fuel economy over long distances. Indeed, as the travelling speed increases, the drag caused by the fix LG becomes significant and a means to retract the LG is required for removing the parasitic effect [1]. In conventional rotorcraft, hydraulic actuators are responsible for LG extension/retraction. Nevertheless, these mechanisms add extra weight, since they include the fluid reservoir, the hydraulic pump and several control valves, which also require periodical maintenance. To overcome these challenges, EMAs are replacing hydraulic actuators in LG extension/retraction systems. This shift is in line with the push towards the more electrical aircraft (MEA) concept [2-4].

Fault-tolerance is highly demanded in EMAs for complying with stringent safety requirements. The basic EMA architecture consists of 1) a power electronics converter (PEC) unit, 2) an electrical machine and 3) a mechanical drive-train. Due to the safety-critical nature of the application, each of these components needs to be designed according to fault-tolerant constraints. Considering the electrical machine, PMSMs are suitable candidates for EMAs, due to their high power density and fault-tolerance capabilities [5-7]. Among the fault-tolerance PMSMs proposed in literature [8-10], those with two separate three-phase windings (also known as dual three-phase winding PMSMs) represent an attractive choice, due to the good compromise between fault-tolerance capability and standard PEC adoption [11-13].

Part of this work was funded by the INNOVATIVE doctoral programme. The INNOVATIVE programme is partially funded by the Marie Curie Initial Training Networks (ITN) action (project number 665468) and partially by the Institute for Aerospace Technology (IAT) at the University of Nottingham.
The design of a fault-tolerant dual three-phase winding PMSM is presented in this work. A 12 slots / 10 poles configuration is employed on an EMA, which performs the extension/retraction of a helicopter nose LG. The EMA's architecture is depicted in Fig. 1, where the two sets of windings are fed by as many PECs. The PMSM performance is evaluated via FE analysis during both healthy and faulty conditions. In particular, the PMSM operations are investigated along with the compensation strategy, when a three-phase short-circuit fault occurs at one winding's terminals. Although three-phase short-circuits (i.e. symmetric faults) are less likely to happen than inter-turns and phase-to-ground faults (i.e. asymmetric faults) [14], a symmetric fault may intentionally be induced in response to an asymmetric fault detection. This strategy allows to reduce both the risk of Permanent Magnets (PMs) demagnetisation and the torque oscillations [15], which may noticeably stress the EMA drive-train. The braking torque developed by the short-circuited winding is balanced acting on the healthy winding for completing the EMA mission. Considering that the braking torque is a function of the rotor speed, two cases are analysed: 1) short-circuit at rated speed and 2) short-circuit at the speed corresponding to the maximum braking torque value. The latter case represents the worst-case scenario for the healthy winding, due to the higher current required for compensating the parasitic torque. Finally, the extension/retraction EMA behaviour (under both healthy and faulty conditions) is simulated, in Dymola environment, using a purposely built dual three-phase PMSM model. This model allows to apply a three-phase short-circuit fault at any simulation instant [16]. The results obtained in Dymola and FE analysis are then compared and discussed. The EMA fault tolerance can be further improved by extending the combined analysis presented in this work to PEC and/or drive-train components.

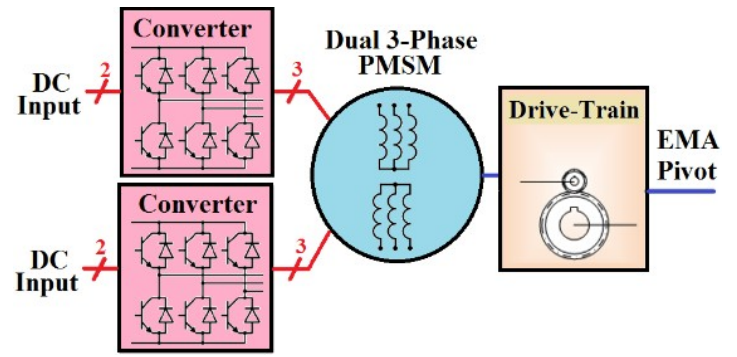

Fig. 1. EMA architeture under analisys.

\section{EMA DESCRIPTION}

The helicopter nose LG under study can be extended and retracted by directly applying $1 \mathrm{kNm}$ torque to its pivot. Hence, the employment of the mechanical device for converting rotational into linear motion (e.g. a roller screw) can be avoided. However, the high torque demand implies the application of two 
stages gearbox [17]. Therefore, the LG pivot is interfaced to a $1^{\text {st }}$ gearbox stage, i.e. a harmonic drive featuring a 200:1 step-down ratio $\left(R_{D H}\right)$, which has been selected due to its high gear ratio and near-zero backlash [18]. A further gear ratio increase is obtained through a $2^{\text {nd }}$ gearbox stage, i.e. a spur gear coupled to the harmonic drive input shaft and featuring a 5:1 step-down ratio $\left(\mathrm{R}_{\mathrm{SG}}\right)$. If gear ratios and the efficiencies $\left(\eta_{D H}\right.$ and $\left.\eta_{S G}\right)$ of both gearbox stages are known, the speed $\left(\Omega_{P M S M}\right)$ and the torque $\left(\tau_{P M S M}\right)$ at PMSM shaft can be respectively determined as in (1) and (2).

$$
\begin{gathered}
\Omega_{P M S M}=\Omega_{L G} \cdot R_{H D} \cdot R_{S G} \\
\tau_{P M S M}=\frac{\tau_{L G}}{R_{H D} \cdot R_{S G} \cdot \eta_{H D} \cdot \eta_{S G}}
\end{gathered}
$$

Considering the worst-case design scenario, a $50 \%$ efficiency is assumed for both gearbox stages, thus resulting in $\tau_{P M S M}=4 \mathrm{Nm}$ and $\Omega_{P M S M}=3000 \mathrm{rpm}$ (i.e. PMSM design specifications).

The LG is required to cover an arc of $120^{\circ} \mathrm{deg}$, ranging from the extended position (i.e. at $0^{\circ} \mathrm{deg}$ ) to the fully retracted one (i.e. at $120^{\circ} \mathrm{deg}$ ), as schematically shown in Fig. 2. Since the LG can travel at a maximum speed of $18^{\circ} \mathrm{deg} / \mathrm{s}$ with a maximum acceleration of $6^{\circ} \mathrm{deg} / \mathrm{s}^{2}$, a minimum time trajectory algorithm has been implemented, with the aim of fulfil the EMA mission in the shortest possible time [19,20]. According to the algorithm, the LG operating time results equal to $10^{\circ} \mathrm{s}$ for extension plus other $10^{\circ} \mathrm{S}$ for retraction. Hence, the PMSM will work with a relatively short-time duty cycle [21].

The EMA electric drive consists of 1) a fault-tolerant dual winding three-phase PMSM, 2) two independent 270 V DC link sources, each supplying one PEC connected to a winding set (see Fig. 1) and 3) the control platform. In terms of PEC architecture, a standard two-level inverter has been selected, due to the relatively low power of the PMSM (i.e. $1.26 \mathrm{~kW}$ mechanical power) and to its well-known modulation strategy.

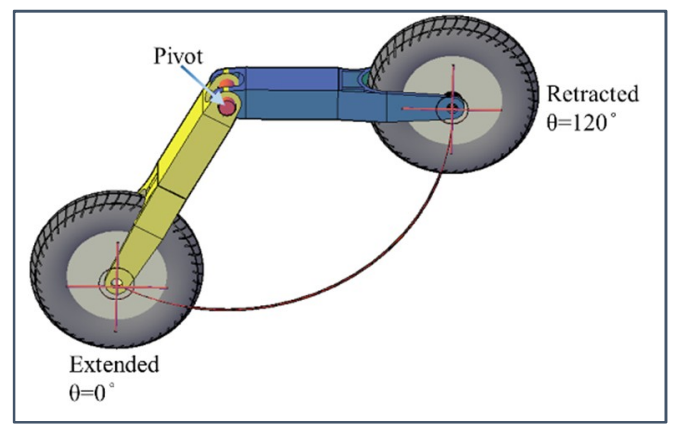

Fig. 2. LG extension/retraction trajectory.

\section{DUAL THREE-PHASE PMSM DESIGN}

The dual three-phase PMSM has been chosen due its inherent redundant and modular structure, which allows to operate the LG even in case of severe windings or PECs faults. A low torque ripple and a high winding factor are achieved by using a 12 slots / 10 poles combination [11] and a concentrated single-layer winding configuration [8], as sketched in Fig. 3. The adopted slots/poles combination is the outcome of a trade-off study. Both winding sets are star-connected and the shift angle between phase $A 1$ and phase $A 2$ axes is equal to zero degrees (see Fig. 3) [11]. Each winding set has been designed to produce $4 \mathrm{Nm}$ at $3000 \mathrm{rpm}$.

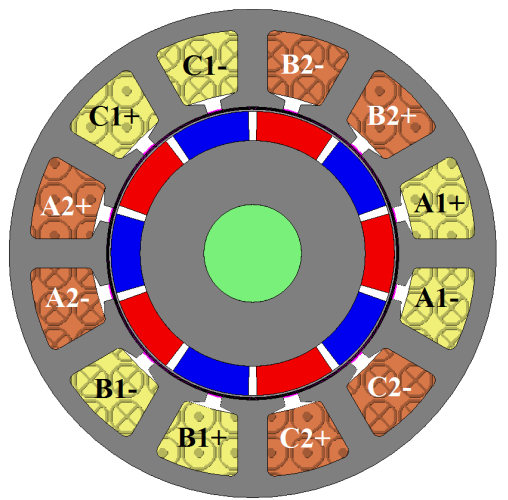

Fig. 3. Geometry and winding layout of the dual three-phase, 12 slots / 10 poles PMSM.

Due to the overload resulting from the compensation strategy implementation, high permeability soft magnetic cobalt-iron alloy (featuring relatively high saturation flux density values) has been selected for both stator core and rotor back iron. Samarium-cobalt PMs are preferred to neodymium-iron-boron PMs, due to the lower residual magnetism. This will induce lower voltage in the short-circuited winding for the same PMs' volume and speed. The short-time duty cycle and the thermal separation between phases (achieved by using concentrated single-layer windings [8]) allow to use a simple aluminium housing equipped with axial fins for thermal management [22, 23].

TABLE I. DUAL THREE-PhASE PMSM PARAMETERS

\begin{tabular}{|c|c|c|}
\hline Parameter & Symbol & Value \\
\hline Rated Speed [rpm] & $\Omega_{\mathrm{PMSM}}$ & 3000 \\
\hline Rated Torque $[\mathrm{Nm}]$ & $\tau_{\mathrm{PMSM}}$ & 4 \\
\hline Rated Current $\left[\mathrm{A}_{\mathrm{pk}}\right]$ & $\mathrm{I}_{\mathrm{n}}$ & 4.8 \\
\hline Phase Resistance $[\Omega]$ & $\mathrm{R}$ & 3.24 \\
\hline d-axis Inductance $[\mathrm{mH}]$ & $\mathrm{L}_{\mathrm{d}}$ & 13.7 \\
\hline q-axis Inductance [mH] & $\mathrm{L}_{\mathrm{q}}$ & 13.7 \\
\hline PM Flux [Wb] & $\Psi_{\mathrm{PM}}$ & 0.112 \\
\hline Stack Length [mm] & $\mathrm{L}$ & 50 \\
\hline Stator Outer Diameter [mm] & $\mathrm{D}_{\mathrm{o}}$ & 50 \\
\hline
\end{tabular}

The analysis of the PMSM described above has been performed using a FE model and the obtained results are provided in the next sub-sections, while the PMSM main data are summarized in Tab. I.

\section{A. PMSM - No-Load Performance}

The PMSM performance is firstly evaluated at no-load. The flux density map and the flux lines distribution at rated speed (i.e. $3000 \mathrm{rpm}$ ) are presented in Fig. 4, while the induced back-electromotive force (Back-EMF) waveforms are shown in Fig. 5. Only the Back-EMFs relative to one three-phase winding are reported in Fig. 5, due to the identical layout and to the zero shift angle between the two windings. Using the Fourier series transformation, the total harmonic distortion (THD) of the Back-EMF has been determined and it is equal to $7 \%$. Further, the amplitude of the fundamental Back-EMF is $124.9 \mathrm{~V}_{\mathrm{rms}}$, whereby the voltage constant $K_{V}$ is $0.0416 \mathrm{~V}_{\text {rms }} / \mathrm{rpm}$. The relatively high THD value is due to the not-refined layout of the armature winding, which features a low number of slots, a concentrated arrangement and a single-layer layout. Nevertheless, the THD is not a critical requirement for the application under study, where main focus is given to the fault tolerance capability of the PMSM. 


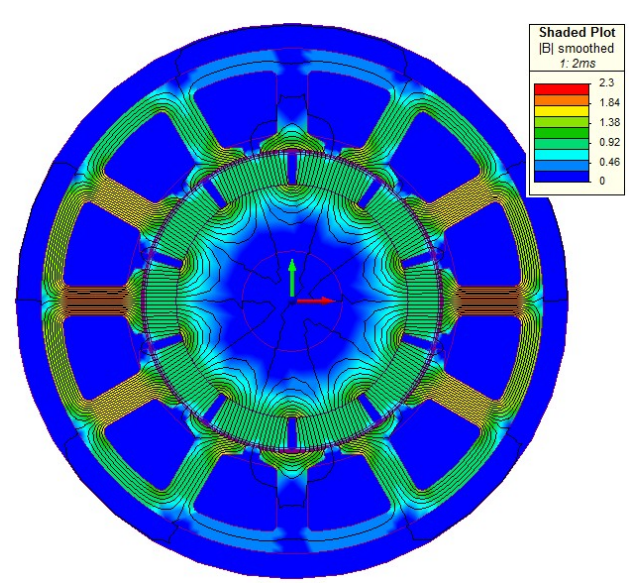

Fig. 4. No-load flux density map and flux lines distribution at $3000 \mathrm{rpm}$.

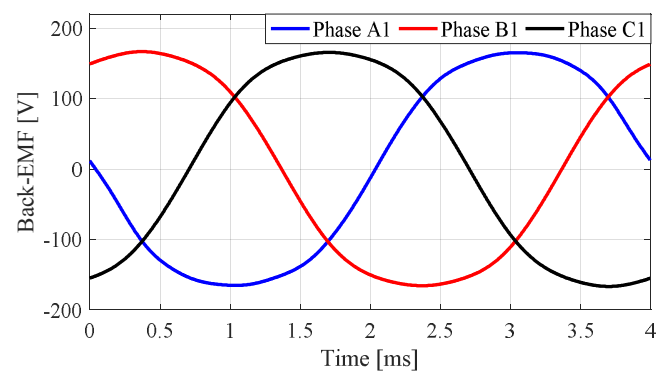

Fig. 5. Back-EMF waveforms at $3000 \mathrm{rpm}$ for one three-phase winding.

\section{B. PMSM-Load Performance}

The dual three-phase PMSM can deliver $4 \mathrm{Nm}$ torque in two different ways: 1 ) one three-phase winding is fed at rated current $\mathrm{I}_{\mathrm{n}}=4.8 \mathrm{~A}_{\mathrm{pk}}$, while the other one is open and 2) both sets of windings are supplied by $2.4 \mathrm{~A}_{\mathrm{pk}}$ (i.e. $\mathrm{I}_{\mathrm{n}} / 2$ ).
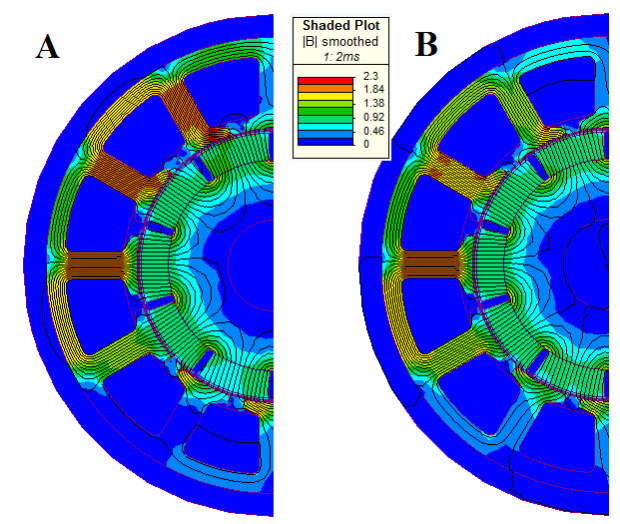

Fig. 6. Flux density map and flux lines distribution at $3000 \mathrm{rpm} \mathrm{A)} 4 \mathrm{Nm}$ feeding only one winding at $4.8 \mathrm{~A}_{\mathrm{pk}}$ and B) $4 \mathrm{Nm}$ supplying both windings at $2.4 \mathrm{~A}_{\mathrm{pk}}$ each

For the two operating modes, the flux density map and the flux lines distribution are reported in Fig. 6, whereas the developed torque is depicted in Fig. 7. As expected, higher saturation is reached when only one winding is fed, especially in the tooth-shoe area (see Fig. 6). In case both windings are employed for developing $4 \mathrm{Nm}$, a $0.5 \%$ increase in the average torque is obtained (see Fig. 7). On the other hand, a lower torque ripple $(0.98 \%$ against $1.04 \%)$ is revealed, when only one winding is supplied. Although the two operating modes are equivalent in terms of performance at the PMSM shaft, the amount of Joule losses generated is different. In fact, when only one winding is fed, the Joule losses are doubled (112 W against $56 \mathrm{~W})$. The torque-current characteristic has been carried out by feeding one winding, as illustrated in Fig. 8. For $q$-axis current values higher than $6 \mathrm{~A}_{\mathrm{pk}}$, the saturation influence on the generated torque is noted, while the torque constant is equal to $0.84 \mathrm{Nm} / \mathrm{A}_{\mathrm{pk}}$ in the linear region.

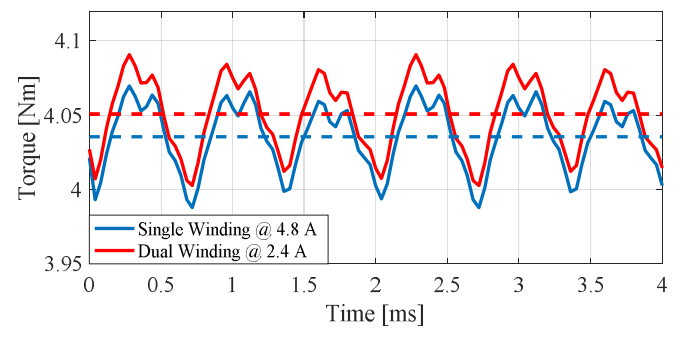

Fig. 7. Instantaneous torque developed by feeding a) one winding with $I_{n}$ (blue) and 2) both windings with $\mathrm{I}_{\mathrm{n}} / 2$ (red)

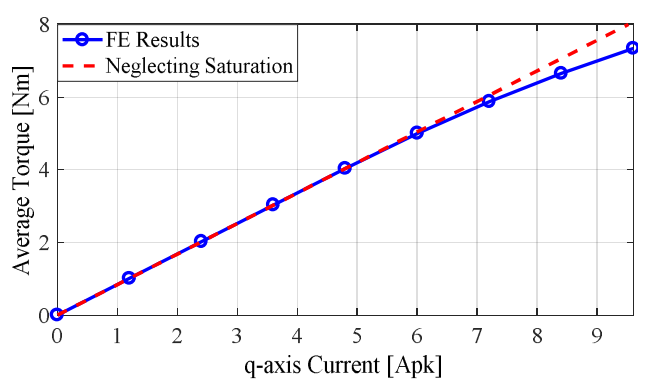

Fig. 8. Torque Vs $q$-axis current curve with (blue) and without (red) magnetic saturation, when only one three-phase winding is fed.

\section{PMSM-Three-Phase Short-Circuit}

In case a three-phase short-circuit occurs on one of the two winding set, the moving PMs continue to induce voltage in the faulty winding and the resulting current is only limited by the PMSM impedance. Besides the uncontrolled short-circuit current (i.e. the PMs' field cannot be controlled or removed), which leads to temperature rise and might irreversibly demagnetise the PMs, a braking torque is measured at the shaft. For the designed PMSM, the braking torque as function of the rotor speed has been determined by means of FE simulations, as shown in Fig. 9.

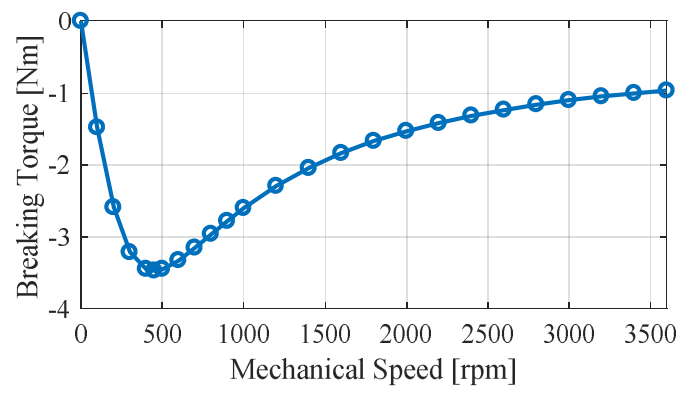

Fig. 9. Braking torque curve obtained by using FE method.

The braking torque peak (i.e. $-3.47 \mathrm{Nm}$ ) is reached at $450 \mathrm{rpm}$, while at rated speed, a braking torque of $-1.1 \mathrm{Nm}$ is delivered. For sake of completeness, the amplitude of the short-circuit current at steady-state is reported in Fig. 10. At rated speed (i.e. $3000 \mathrm{rpm}$ ), the amplitude of the current flowing through the faulty winding is equal to $8.03 \mathrm{~A}_{\mathrm{pk}}$. However, only the $q$-axis component of this current is responsible for the braking torque. 


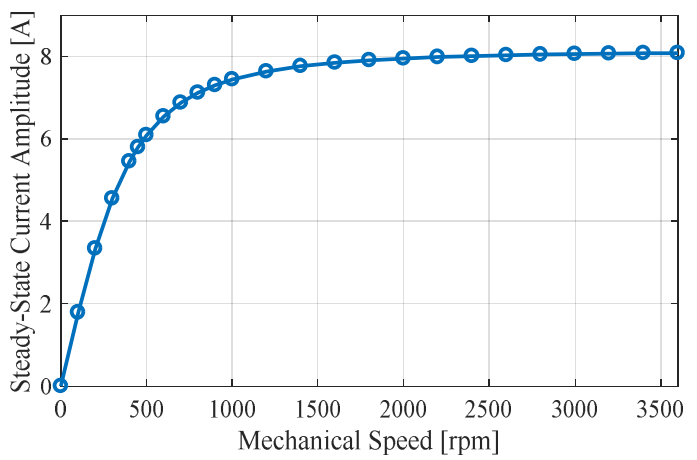

Fig. 10. Amplitude of the short-circuit current at steady-state obtained by using FE method.

\section{PMSM-Compensation Strategy}

The braking torque acts against the PMSM speed and may cause mechanical failures to the drive-train. Also, its presence compromises the EMA mission and a prompt corrective action is required for its compensation. The adopted compensation strategy consists in increasing the $q$-axis current in the healthy winding to produce more torque.

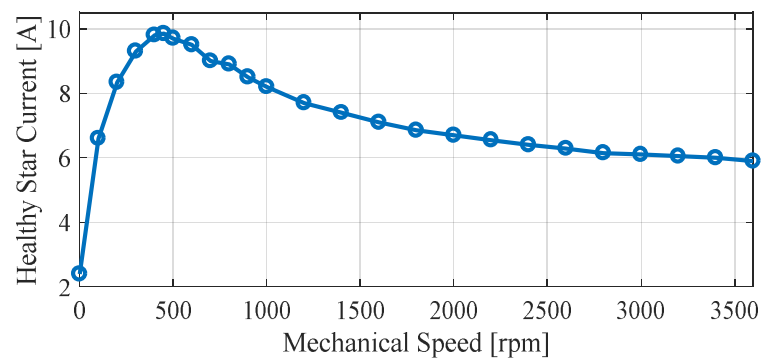

Fig. 11. $q$-axis current applied during the compensation startegy.

Fig. 11 reports the current compensation for each simulated short-circuit's speed. At rated speed, the needed current is equal to $6.1 \mathrm{~A}_{\mathrm{pk}}$ (i.e. $127 \%$ of $\mathrm{I}_{\mathrm{n}}$ ), while $9.85 \mathrm{~A}_{\mathrm{pk}}\left(205 \%\right.$ of $\left.\mathrm{I}_{\mathrm{n}}\right)$ are necessary at $450 \mathrm{rpm}$. Although an approximately doubled rated current is necessary in the most challenging condition, the PMSM thermal management is not compromised. Indeed, the machine thermal dynamics are much lower than those related to the overload, which in the worst-case can last $20 \mathrm{~s}$ (i.e. one extension/retraction). Further, a reasonable safety-margin is ensured by selecting an appropriate thermal class (e.g. $180{ }^{\circ} \mathrm{C}$ or $200^{\circ} \mathrm{C}$ ) for the enamel magnet wire [21]. In terms of PECs, these must be designed for handling the overload in order to make the compensation strategy successful. The effectiveness of the compensation strategy is verified by means of FE simulations, considering two faulty conditions: 1) short-circuit at $3000 \mathrm{rpm}$ and 2) short-circuit at $450 \mathrm{rpm}$. Firstly, the fault condition at rated speed is analysed. In Fig. 12, the torque (top sub-plot) and the phase currents in both windings (middle and bottom sub-plots) are shown for three operating conditions:

- Fully healthy condition - both windings are supplied at $\mathrm{I}_{\mathrm{n}} / 2$ (i.e. $2.4 \mathrm{~A}_{\mathrm{pk}}$ ) and the PMSM develops $4 \mathrm{Nm}$, from 0 to $7.87 \mathrm{~ms}$.

- Faulty condition with no compensation - at $7.87 \mathrm{~ms}$, a threephase short-circuit is applied to one winding, while the current in the other is kept unchanged. Thus, from 7.87 to $40 \mathrm{~ms}$, the PMSM operates in faulty condition without compensation strategy. During the transient, the torque peak is equal to $-4.96 \mathrm{Nm}$ and $13.3 \mathrm{~A}_{\mathrm{pk}}$ is the current peak (these instantaneous values vary according to the fault injection instant). At steady-state, the average torque at the PMSM shaft is equal to $0.9 \mathrm{Nm}$ (this value compromises the EMA mission), while $8.03 \mathrm{~A}_{\mathrm{pk}}$ flow through the faulty winding.
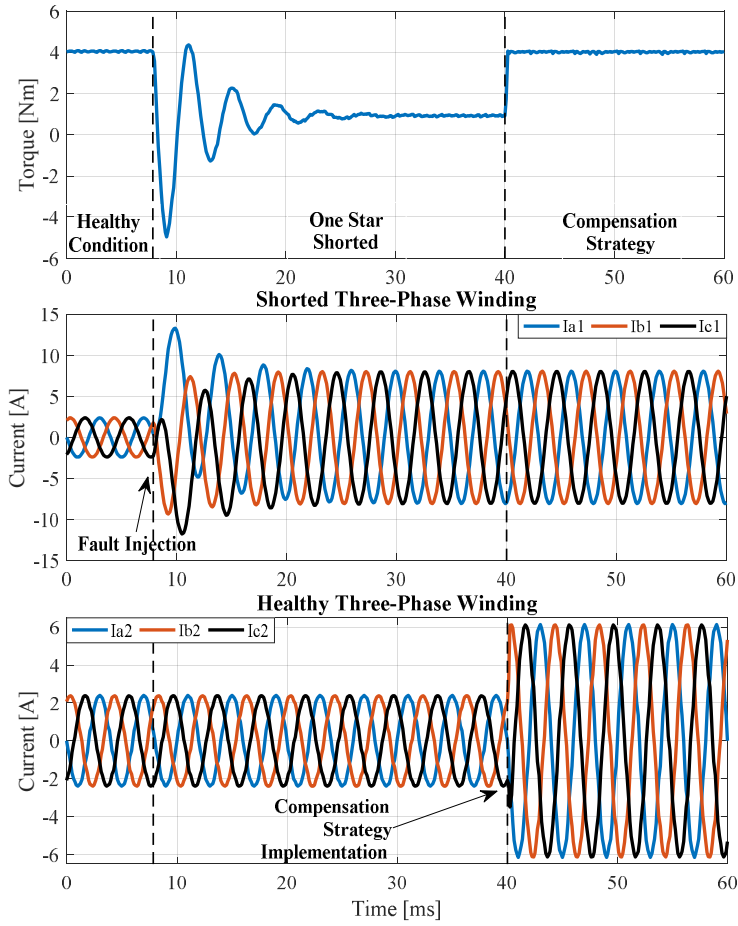

Fig. 12. PMSM operations at $3000 \mathrm{rpm}$ during pre-fault and post-fault (with and without compensation strategy): a) torque (top sub-plot), b) phase currents in the faulty winding (middle sub-plot) and c) phase currents in the healthy winding (bottom sub-plot).
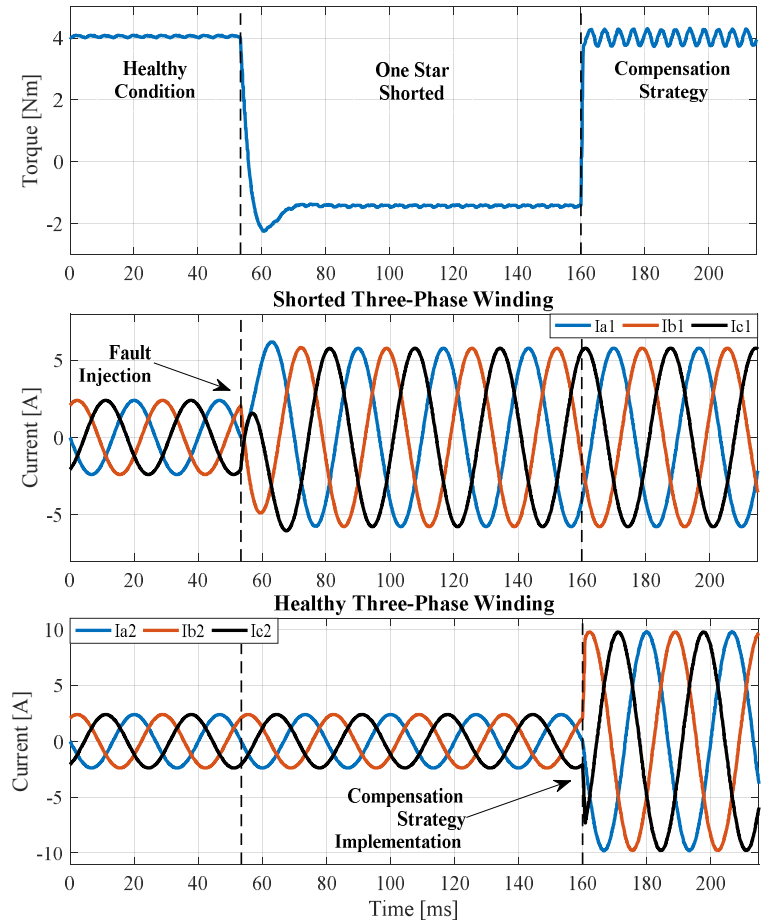

Fig. 13. PMSM operations at $450 \mathrm{rpm}$ during pre-fault and post-fault (with and without compensation strategy): a) torque (top sub-plot), b) phase currents in the faulty winding (middle sub-plot) and c) phase currents in the healthy winding (bottom sub-plot). 
- Faulty condition with compensation - at $40 \mathrm{~ms}$, the compensation strategy is triggered by increasing the current in the healthy winding from $2.4 \mathrm{~A}_{\mathrm{pk}}$ to $6.13 \mathrm{~A}_{\mathrm{pk}}$. Hence, the torque increases up to $4 \mathrm{Nm}$, with $6.22 \%$ ripple and the PMSM operates with one winding short-circuited, from 40 to $60 \mathrm{~ms}$.

The same study is also performed for the worst-case faulty scenario, occurring at $450 \mathrm{rpm}$. The relative results are depicted in Fig. 13. In this case, the fault is applied at $53 \mathrm{~ms}$ and the braking torque (i.e. $-3.47 \mathrm{Nm}$ ) exceeds the one generated by the healthy winding (i.e. $2 \mathrm{Nm}$ ), leading to $-1.47 \mathrm{Nm}$ of resultant torque on the shaft. At $160 \mathrm{~ms}$, the compensation strategy is implemented by increasing the current in the healthy winding from $2.4 \mathrm{~A}_{\mathrm{pk}}$ to $9.85 \mathrm{~A}_{\mathrm{pk}}$, thus the rated torque value is restored, although a $7.3 \%$ ripple is registered.

\section{EMA MODEL AND SIMULATION RESUltS}

For a more comprehensive and system-level performance analysis, the EMA described in Section II has been built in Dymola environment. The EMA described in Section II has been built in Dymola environment, in order to investigate the performance at system-level. In Fig. 14, the EMA model used during the simulations is shown. For the drive-train, the blocks available in Dymola library have been used, whereas, purposely-built models have been developed for the electric drive components [16].

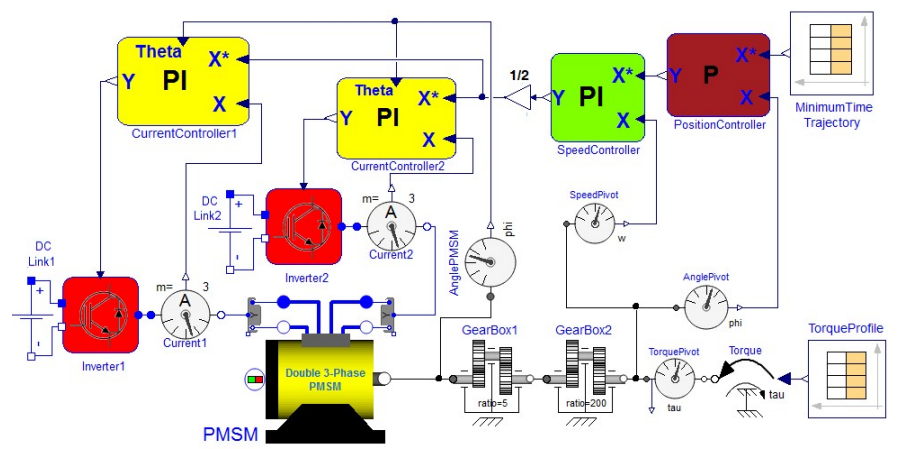

Fig. 14. EMA simuation model in Dymola enviroment.

The LG position tracking is achieved by adopting a minimum time trajectory, as position reference signal. The trajectory is defined by: 1) the final position (i.e. $120 \mathrm{deg}$ ), 2) the maximum speed (i.e. $18^{\circ} \mathrm{deg} / \mathrm{s}$ ) and 3 ) the maximum acceleration (i.e. $6^{\circ} \mathrm{deg} / \mathrm{s}^{2}$ ). Starting from the initial position, the maximum acceleration is developed until the speed reaches its maximum value, then the trajectory is travelled at maximum speed. Approaching the end position, the LG slows down with the maximum deceleration, until the speed reaches the null value. The implemented trajectory is provided in Fig. 15 (top and middle sub-plots), where the main LG kinematic stages are highlighted. LG position is controlled by a cascaded structure, where the inner loops supervise the $q$-axis currents in both windings, the outer loop controls the LG speed and finally the outermost loop regulates the LG position. The $d$-axis current set-points are set to zero. The EMA behaviour in healthy condition (with both windings supplied at $I_{n} / 2$ ) is summarized in Fig. 15, where a fair position tracking error is achieved. A slight mismatch between actual and reference pivot torques can be observed during the EMA acceleration/deceleration. This is due to the acceleration/deceleration torque required by the minimum time trajectory.
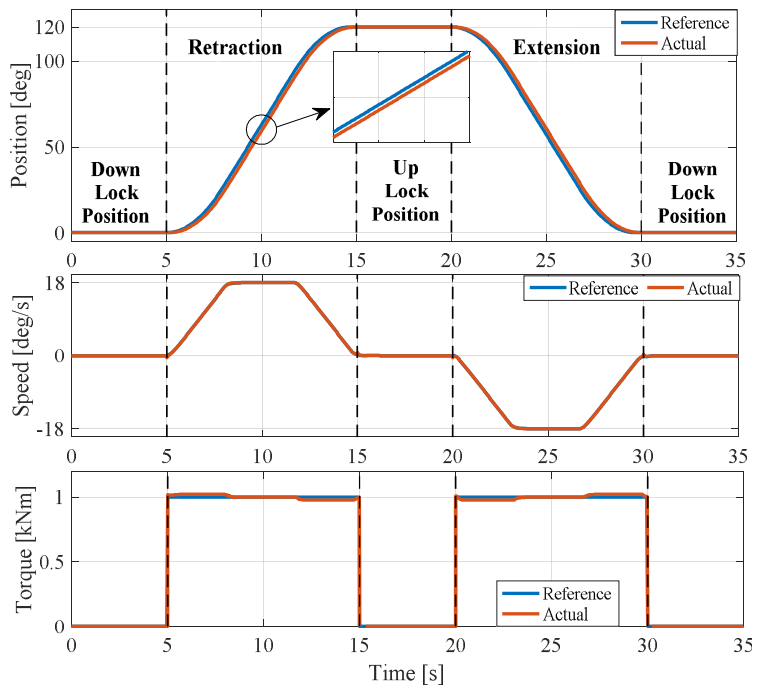

Fig. 15. Mechanical quantities at the LG pivot in healthy condition under minimum time trajectory tracking.

As discussed in Section III.D, the most challenging faulty condition for the PMSM is represented by short-circuit at $450 \mathrm{rpm}$. Nevertheless, $450 \mathrm{rpm}$ is just a transition speed according to the EMA speed profile (middle sub-plot in Fig. 15). In other words, the LG pivot keeps such speed only for a fraction of second, while most of the trajectory is travelled at $3000 \mathrm{rpm}$. For this reason, the short-circuit fault at $3000 \mathrm{rpm}$ can be safely considered as the most likely faulty condition.
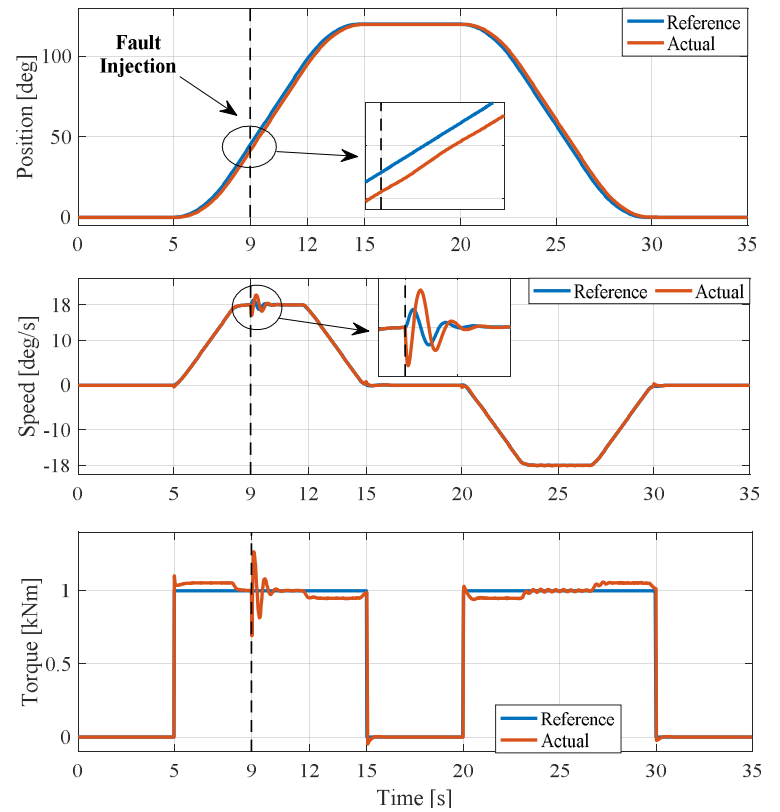

Fig. 16. Mechanical quantities at the LG pivot in case of fault injection at $9 \mathrm{~s}$.

In the simulated system, the compensation strategy is applied as soon as the fault is injected, due to the prompt current controller action. In Fig. 16, position, speed and torque at the LG pivot are reported, when the three-phase short-circuit is injected at $9 \mathrm{~s}$ (PMSM speed $3000 \mathrm{rpm}$ ). During the post-fault transient (from 9 to $10.2 \mathrm{~s}$ ), oscillations are present in both torque and 
speed at the LG pivot. Despite these oscillations, which affect the tracking error, the position reference is still tracked. At steady-state (from $10.2 \mathrm{~s}$ onward), the EMA is able to complete its mission, with the same tracking performance as in the healthy condition. The $q$-axis current dynamic for both windings is shown in Fig. 17. Before the fault injection, both windings are fed with $\mathrm{I}_{\mathrm{n}} / 2$ along the $q$-axis. After the fault transient when the speed is still equal to $3000 \mathrm{rpm}$ (from 9 to $12 \mathrm{~s}$ ), the $q$-axis current in the healthy winding is $5.95 \mathrm{~A}_{\mathrm{pk}}$ (against $6.13 \mathrm{~A}_{\mathrm{pk}}$ from FE). Instead, its maximum of $8.58 \mathrm{~A}_{\mathrm{pk}}$ (against $9.85 \mathrm{~A}_{\mathrm{pk}}$ from $\mathrm{FE}$ ) is reached at $450 \mathrm{rpm}$, as expected. The lower compensation current values obtained from Dymola simulation are consistent seeing that the implemented dual three-phase PMSM model does not include the magnetic saturation. Indeed, higher current is required for developing the same torque when magnetic saturation is considered. While the EMA is accelerating/decelerating, the trend of current in the healthy winding mirrors the correction strategy's current shown in Fig. 12.

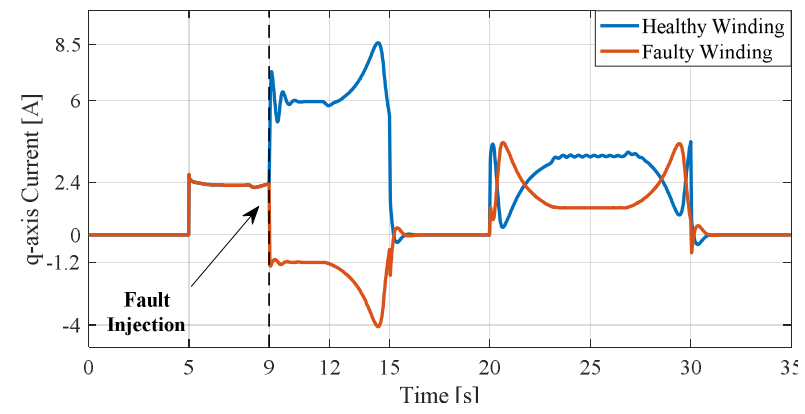

Fig. 17. $q$-axis current in both healthy (blue line) and faulty (red line) windings in case of fault injection at $9 \mathrm{~s}$.

\section{CONCLUSIONS}

In this paper, the design of a fault-tolerant dual three-phase winding PMSM was presented. The PMSM performance was evaluated via FE analysis, in several operating conditions, including no-load, full-load and three-phase short-circuit of one winding. To balance the braking torque resulting from the three-phase short-circuit, a compensation strategy was investigated and the corrective $q$-axis current values were determined. The compensation strategy success is subordinate to the PEC capability of handling the overload. Finally, system-level simulations were performed in Dymola environment, for both healthy and faulty conditions, since the designed PMSM is part of an EMA for helicopter nose LG extension/retraction. Dymola models considering faults on PEC and drive-train components are under development. These tools will help the EMA designer in improving the fault tolerance at system-level by minimizing the faults impact. In addition, the PMSM design optimization is currently on going for better exploiting the soft magnetic material and achieving further weight reduction.

\section{REFERENCES}

[1] I. Moir and A. Seabridge, "Electrical Systems," in Aircraft systems: mechanical, electrical and avionics subsystems integration. ISBN: 1119965209. vol. 52, ed: John Wiley \& Sons, 2011, pp. 181-237.

[2] V. Madonna, P. Giangrande, and M. Galea, "Electrical Power Generation in Aircraft: review, challenges and opportunities," in press on IEEE Transactions on Transportation Electrification, DOI: 10.1109/TTE.2018.2834142, 2018.
[3] J. A. Rosero, J. A. Ortega, E. Aldabas, and L. Romeral, "Moving towards a more electric aircraft," IEEE AES Magazine, vol. 22, pp. 3-9, 2007.

[4] C. I. Hill, S. Bozhko, Y. Tao, P. Giangrade, and C. Gerada, "More Electric Aircraft Electro-Mechanical Actuator Regenerated Power Management," in 2015 IEEE 24th International Symposium on Industrial Electronics, pp. 337-342, 2015.

[5] C. Gerada, M. Galea, and A. Kladas, "Electrical machines for aerospace applications," in 2015 IEEE WEMDCD 2015, pp. 79-84.

[6] S.A Odhano, P.Giangrande, R.Bojoi and Gerada, "Self-commissioning of interior permanent magnet synchronous motor drives with high-frequency current injection," 5th Annual IEEE Energy Conversion Congress and Exhibition, pp. 3852-3859, 2013.

[7] A. Al-Timimy, P.Giangrande, M. Degano, M. Galea and C. Gerada, "Comparative study of permanent magnet-synchronous and permanent magnet-flux switching machines for high torque to inertia applications," 2017 IEEE Workshop on Electrical Machines Design, Control and Diagnosis, pp. 45-51, 2017.

[8] B. C. Mecrow, A. G. Jack, J. A. Haylock, et al., "Fault-tolerant permanent magnet machine drives," IEEE EPA Proc., vol. 143, pp. 437-442, 1996.

[9] A. Al-Timimy, M. Degano, Z. Xu, G. Lo Calzo, P. Giangrande, M. Galea, C. Gerada, H. Zhang, and L. Xia, "Trade-off analysis and design of a high power density PM machine for flooded industrial pump," in 2016 Annual Conference of the IEEE Industrial Electronics Society, pp. 1749-1754, 2016.

[10] L.P. Di Noia and R. Rizzo, "Design of a five-phase permanent-magnet motor for the electric steering of an aircraft nose landing gear," in IET Electrical System in Transportation, vol. 7, pp. 327-333, 2017.

[11] M. Barcaro, N. Bianchi and F. Magnussen, "Faulty Operations of a PM Fractional-Slot Machine With a Dual Three-Phase Winding," IEEE Transactions on Industrial Electronics, vol. 58, pp. 3825-3832, 2011.

[12] B. Basler, T. Greiner and P. Heidrich, "Fault-Tolerant Strategies for Double Three-Phase PMSM used in Electronic Power Steering Systems," in 2015 IEEE Transportation Electrification Conference and Expo.

[13] A. Al-Timimy, P. Giangrande, M. Degano, Z. Xu, M. Galea, C. Gerada, G. Lo Calzo, H. Zheng, and L. Xia, "Design and Losses Analysis of a High Power Density Machine for Flooded Pump Applications" in IEEE Trans. On Industry Applications, vol. 54, no. 4, pp. 3260-3270, 2018.

[14] G. Paoletti, and A. Golubev, "Partial discharge theory and applications to electrical systems," in Industry Technical Conference Record Annual, pp.124,138, 21-25 June 1999.

[15] B.A. Welchko, T.M. Jahns, W.L. Soong, et al, "IPM synchronous machine drive response to symmetrical and asymmetrical short circuit faults," in IEEE Tran. on Energy Conversion, vol. 18, pp. 291-298, 2003.

[16] P.Giangrande, C.I.Hill, S.V.Bozhko, and C. Gerada, "A novel multi-level electro-mechanical actuator virtual testing and analysis tool," in 2014 IET Conference on Power Electronics, Machines and Drives, pp. 1-6, 2014.

[17] J.W. Bennet, B.C. Mecrow. A.G. Jack, et al., "A Prototype Electrical Actuator for Aircraft Flaps" in IEEE TIA, vol. 46, n. 3, pp. 915-921, 2010.

[18] C. Sciascera, P. Giangrande, C. Brunson, M. Galea and C. Gerada, "Optimal design of an electro-mechanical actuator for aerospace application," in 2015 Annual Conference of the IEEE Industrial Electronics Society, pp. 1903-1908, 2015.

[19] F. Cupertino, G. Pellegrino, P. Giangrande, L. Salvatore, "Model based design of a sensorless control scheme for permanent magnet motors using signal injection," in 2010 Energy Conversion Congress and Exposition, pp. 3139-3146, 2010.

[20] P. Giangrande, F. Cupertino and G. Pellegrino, "Modelling of linear motor end-effects for saliency based sensorless control," in 2010 IEEE Energy Conversion Congress and Exposition, pp. 3261-3268, 2010.

[21] C. Sciascera, M. Galea, P. Giangrande, and C. Gerada, "Lifetime consumption and degradation analysis of the winding insulation of electrical machines," in 2016 IET Conference on Power Electronics Machines and Drives, pp. 1-5, 2016.

[22] Z. Xu, A. Al-Timimy, M. Degano, P. Giangrande, G. Lo Calzo, H. Zhang, M. Galea, C. Gerada, S. Pickering, and L. Xia, "Thermal management of a permanent magnet motor for a directly coupled pump," in 2016 International Conference on Electrical Machines, pp. 2738-2744, 2016.

[23] C. Sciascera, P. Giangrande, L. Papini, C. Gerada, and M. Galea, "Analytical Thermal Model for Fast Stator Winding Temperature Prediction," in IEEE Transactions on Industrial Electronics, vol. 64, n. 8, pp. 6116-6126, March 2017. 